\title{
WHAT FACTORS INFLUENCE THE EARNINGS OF GENERAL PRACTITIONERS AND MEDICAL SPECIALISTS? EVIDENCE FROM THE MEDICINE IN AUSTRALIA: BALANCING EMPLOYMENT AND LIFE SURVEY
}

\author{
TERENCE CHAI CHENG ${ }^{\mathrm{a}, *}$, ANTHONY SCOTT ${ }^{\mathrm{a}}$, SUNG-HEE JEON $^{\mathrm{a}}$, GUYONNE KALB $^{\mathrm{a}}$, \\ JOHN HUMPHREYS ${ }^{\mathrm{b}}$ and CATHERINE JOYCE ${ }^{\mathrm{c}}$ \\ ${ }^{a}$ Melbourne Institute of Applied Economic and Social Research, The University of Melbourne, Melbourne, Victoria, Australia \\ School of Rural Health, Monash University, Melbourne, Victoria, Australia \\ ${ }^{\mathrm{c}}$ Department of Epidemiology and Preventive Medicine, Monash University, Melbourne, Victoria, Australia
}

\begin{abstract}
SUMMARY
To date, there has been little data or empirical research on the determinants of doctors' earnings despite earnings having an important role in influencing the cost of health care, decisions on workforce participation and labour supply. This paper examines the determinants of annual earnings of general practitioners (GPs) and specialists using the first wave of the Medicine in Australia: Balancing Employment and Life, a new longitudinal survey of doctors. For both GPs and specialists, earnings are higher for men, for those who are self-employed and for those who do after-hours or on-call work. GPs have higher earnings if they work in larger practices, in outer regional or rural areas, and in areas with lower GP density, whereas specialists earn more if they have more working experience, spend more time in clinical work and have less complex patients. Decomposition analysis shows that the mean earnings of GPs are lower than that of specialists because GPs work fewer hours, are more likely to be female, are less likely to undertake after-hours or on-call work, and have lower returns to experience. Roughly $50 \%$ of the income gap between GPs and specialists is explained by differences in unobserved characteristics and returns to those characteristics.
\end{abstract}

Received 11 July 2010; Revised 23 May 2011; Accepted 25 July 2011

JEL Classification: I11; J30; I18

KEY WORDS: earnings; general practitioners; specialists; hedonic regression; decomposition

\section{INTRODUCTION}

The earnings of doctors have an important influence on doctors' labour supply decisions and on overall healthcare costs. The level of earnings is determined partly by the institutional setting, including the method of remuneration, the existence of bargaining agreements with third-party payers, the existence of monopsony power, fee controls and the ability to charge co-payments to patients. These influence the flexibility of earnings in response to changes in market conditions. Where earnings are flexible, the theory of compensating wage differentials hypothesises that earnings are influenced by the relative advantages and disadvantages of jobs, including job characteristics as well as the characteristics of geographic areas, such as a high cost of living (Rosen, 1986). The degree of competition also may influence earnings. This depends on the strength of the demand side, which

*Correspondence to: Melbourne Institute of Applied Economics and Social Research, The University of Melbourne, Alan Gilbert Building, Parkville Victoria 3010, Australia. E-mail: techeng@unimelb.edu.au 
is usually assumed to be relatively weak in health care because of asymmetry of information between doctors and patients. Doctors' own experience, sector of work, reputation, preferences and practice style also are likely to influence their earnings conditional on the institutional and specialty setting.

Earnings also differ by medical specialty, which can influence doctors' choice of specialty. 'Procedural' specialties, such as surgery, typically command higher earnings than 'cognitive' specialties such as general or family practice, and these differentials can exacerbate shortages of general practitioners (GPs). Shortage of GPs is an important policy issue in many countries where the number of specialists continue to rise relative to GPs but where the increasing burden of chronic disease suggests that more GPs are needed relative to specialists. The source of the differences in earnings provides important information for the development of policies aimed at reducing the earnings gap to encourage more doctors to choose general practice as their specialty of choice.

There have been only a handful of studies examining the determinants of doctors' earnings. In a recent paper, Morris et al. (2010) examined the determinants of GP wages in England and found that net income and wages depend on gender, experience, the length of GPs' patient lists, partnership and employment type. The earnings of doctors also have been analysed in the context of the effect of earnings on hours worked (Rizzo and Blumenthal, 1994; Baltagi et al., 2005); earnings and job satisfaction on hours worked (Ikenwilo and Scott, 2007); earnings on choice of work in the public or private sector (Sæther, 2005); and gender differences in the earnings of doctors (Ohsfeldt and Culler, 1986; Gravelle and Hole, 2008). There are few studies comparing the relative earnings of doctors in different specialties, in particular GPs and medical specialists, and the differential effects that doctors' personal and work characteristics may have on earnings of GPs and specialists.

In Australia, total expenditure on medical services was $\$ 18$ billion and accounted for $18.7 \%$ of the total recurrent health expenditure in 2007-2008 (Australian Institute of Health and Welfare (AIHW), 2009). From 2003-2004 to 2007-2008, the cost of medical services, which is composed largely of payments to doctors through Medicare, grew 4.2\% in real terms per year. This is higher than the real wage growth of $1.7 \%$ for the general working population (Australian Bureau of Statistics 2004, 2007). Although some information is available on the salaries of doctors working in public hospitals, very little is known about the earnings of GPs and medical specialists in private practice who are remunerated on a fee-for-service basis. There are no reliable data on the personal annual or hourly earnings of these doctors, especially after deducting practice costs and expenses. Hourly earnings net of practice costs and expenses are the most likely factors influencing the labour supply decisions of doctors.

Doctors in Australia work in both public and private sectors and in a variety of settings such as private practices, hospitals, community health centres, laboratories and radiology facilities. Their earnings are partly determined by the different sources of funding for doctors' services. Doctors in private practice in Australia include most GPs and medical specialists who work outside of public hospitals and who charge patients a fee for each visit or procedure performed. Doctors can charge patients what the market will bear, and either doctors or patients can claim a fixed rebate from Medicare as set out in the Medicare Benefits Schedule (MBS). The MBS details the range of consultations, procedures and tests that are funded under Medicare and the corresponding MBS benefit or rebate. GPs and specialists in private practice are free to set the level of their fees at or above the MBS rebate, with patients paying the difference between the fees charged and the MBS rebate. In addition to Medicare, doctors derive income through a variety of Commonwealth, State and Territory government programs such as services provided through the Department of Veterans' Affairs and WorkCover authorities. For GPs, additional sources include the practice incentives program and payments that are associated with activities such as after-hours care, management of patients with complex and chronic conditions, the provision of care in rural and remote locations, and teaching. Medical specialists who work in private hospitals are paid income from fees from patients, who are eligible to claim back the fixed rebates from Medicare. Medical specialists in public hospitals are usually paid a salary (salaried specialist) or by contract (visiting medical officer), with the level being determined by state bargaining agreements. In addition, some salaried specialists have rights to private practice (RPP). This means that additional income can be earned from seeing private patients, either in a public hospital or in a private setting. 
In this paper, we analyse the determinants of annual earnings of qualified GPs and medical specialists using the first wave of the Medicine in Australia: Balancing Employment and Life (MABEL), a new longitudinal survey of doctors. We estimate a hedonic earnings model for GPs and specialists using the usual human capital variables (e.g. experience and qualifications) in addition to job characteristics and geographical variables. Given that earnings and working hours are likely to be jointly determined, we also address the issue of endogeneity of working hours using an instrumental variable approach. Our results indicate that doctors' earnings are associated with gender, experience, the size of the GP practice, employment type, specialty and the characteristics of doctors' location of work in Australia. We also investigate the source of differences between the earnings of GPs and medical specialists by means of a decomposition analysis.

The paper is organised as follows: Section 2 discusses the data, whereas Section 3 describes the variables and methods used. Section 4 presents the descriptive statistics of dependent and explanatory variables, followed by the results on the endogeneity of the hours variable and the earnings regressions, and the decomposition analysis. Section 5 contains a discussion of the results and highlights some potential policy implications.

\section{DATA}

This study uses data on qualified GPs and specialists from the first wave of the MABEL survey. MABEL is a prospective cohort study of workforce participation, labour supply and its determinants among Australian doctors. The population of interest is all doctors providing clinical medical services in Australia. The sampling frame of the study is the Australian Medical Publishing Company's Medical Directory, a national database managed by the Australian Medical Association. In the first wave, a total of 54750 doctors across four broad groups within the clinical medical workforce (this is the full population of doctors in Australia) were invited to participate. The four groups are GPs, medical specialists, specialists-in-training and hospital non-specialists. This paper examines the first two groups.

Data collection for the first wave was conducted from June to December 2008. The survey questionnaire covered topics such as job satisfaction and attitudes to work, characteristics of work setting (public/private hospital, private practice), workload (hours worked, on-call), finances (income, income sources), geographic location, demographics (including specialty, qualifications) and family circumstances (partner and children).

The overall response rate for the first wave of the survey was $19.36 \%$, with a total of 10498 doctors in the baseline cohort. This includes 3906 GPs (which includes 226 GP registrars), 4597 specialists, 1072 specialistsin-training and 924 hospital non-specialists. The cohort was found to be nationally representative with respect to age, gender, geographic location and hours worked. The methods of the study and characteristics of the baseline cohort are discussed in more detail in Joyce et al. (2010).

\section{METHODS AND DESCRIPTION OF VARIABLES}

\subsection{Econometric model}

We first estimate a hedonic earnings model for GPs and specialists separately using log linear estimation. The earnings question asked in the survey was the following: 'What are your (approximate) total personal earnings from all of the work you do as a doctor? (If possible, base this on your last personal income tax return or pay slip)'. Doctors were then given the option of reporting either annual or fortnightly earnings, both before and after tax was taken out. The measure of doctors' remuneration of interest in this study is the annual gross personal earnings. Although many studies on doctors' earnings (e.g. Langwell, 1982; Ohsfeldt and Culler, 1986) use hourly wages (total earnings divided by total hours worked), an earnings model where the hourly wage is the dependent variable is misspecified when earnings are not proportional to hours and if the number of hours worked is omitted as an explanatory variable (Gravelle and Hole, 2008). When choosing annual earnings instead 
of hourly wages as the dependent variable, the number of hours worked is required as an explanatory variable in the earnings function because income increases with hours worked. The measure of the number of hours worked by doctors defined in this study is the total hours worked per year across a variety of settings (e.g. private consulting rooms, hospital and aged care facility). This is calculated as the product of the total weekly hours worked and the number of weeks worked per year. The number of weeks worked per year is calculated as 52 weeks minus the number of weeks of maternity leave and weeks off work for other reasons (not including annual leave or sick leave) as reported in the survey. ${ }^{1}$ We take the natural logarithm of earnings and hours so that the coefficient on hours measures the percentage change in earnings resulting from a $1 \%$ change in hours.

Hours worked are jointly determined with annual earnings because doctors are likely to have opportunities to work flexible hours. If the hours variable is endogenous, the estimation of the earnings regression using ordinary least squares (OLS) may result in biased estimates. To address the problem of endogeneity in the hours variable, we estimate the earnings function using both OLS and two-stage least squares (2SLS) regressions. A binary variable indicating whether the respondent has children under the age of 5 years is used as instrument. For both the GPs and specialists regressions, observations are clustered by doctors' work postcodes to account for correlation in earnings and hours within local areas that reflect the unobservable characteristics such as competition among doctors and hospital human resource practices.

\subsection{Individual characteristics of general practitioners and specialists}

Doctors' earnings are expected to be influenced by human capital variables (Mincer, 1997) such as their education and professional qualifications, experience and field of specialty. We included variables that indicate whether doctors completed their basic medical training in Australia or overseas and attained fellowship of specialty colleges and the number of postgraduate medical qualifications other than fellowships. Work experience, defined as the number of years because the completion of the basic medical degree less time spent out of clinical practice, also is included as an explanatory variable. For specialists, a set of 18 binary variables that represent doctors' primary clinical specialty was included to capture variations in earnings arising from differences in the type of, and demand for, services provided by doctors. Two additional separate binary variables that indicate the gender of the doctor and whether the doctor is on a temporary work visa are included.

\subsection{Employment type, work setting and practice characteristic}

How doctors are paid also will influence their earnings. The earnings of self-employed doctors may be more flexible as most will be paid by fee-for-service or have locally negotiated contracts. Indicators for employment type and remuneration mode of doctors were constructed using information on doctors' business relationship with their medical practices (e.g. principals/partners, associates, salaried and contracted employees, and locums) and hospital remuneration arrangements (e.g. fee-for-service/direct billing, fixed payments and salary with or without RPP). These modes were assigned based on whether the doctor's primary work environment, defined as where the doctors spend the most hours, is within a hospital (both public and private) or outside of a hospital (e.g. private rooms, community health centres). GPs were grouped into two employment type categories: (i) principals, associates, independent contractors and solo practitioners; and (ii) salaried and contracted employees and locums. GPs in the former category are either owners of GP practices or are generally considered as being self-employed. For specialists, information on doctors' relationships with their medical practice, hospital remuneration types and work settings were combined to form eight employment type and work setting categories: (i) self employed hospital specialists; (ii) self employed non-hospital specialists; (iii) hospital

\footnotetext{
${ }^{1}$ As opposed to maternity leave, holidays and sick leave are counted in the working weeks because these are generally paid leave types. If we leave out holidays and sick leave, the average weeks worked per year is 46.3 and 46.1 for GPs and specialists, respectively. The effect of hours worked on annual earnings would be underestimated if doctors are entitled to paid maternity or parental leave. This is not likely to have any significant effect on the results. In the sample analysed, only 23 GPs and 29 specialists had taken more than 12 weeks of maternity (paternity) leave in the year prior to the survey.
} 
specialists on fixed payment (per session or hour); (iv) hospital specialists salaried without RPP; (v) hospital specialists salaried with RPP; (vi) non-hospital contracted specialists; (vii) non-hospital salaried specialists; and (viii) hospital and non-hospital specialists who are locum or other. We also included a set of binary variables that describe the number of full-time and part-time doctors working in a practice to examine how practice size influences doctors' income.

\subsection{Jobcharacteristics}

The central theme in the theory of compensating differentials is that in a well-functioning labour market where wages are flexible, the equilibrium market wage will reflect the relative advantages and disadvantages of jobs (Rosen, 1986). In the medical profession, non-pecuniary job characteristics, such as unpredictable working hours, work stress and the degree of social and geographical isolation that comes with working in a remote area, may influence doctors' earnings. Self-reported measures of doctors' job characteristics were included in the earnings equations for GPs and specialists. These measures include the extent to which doctors agree (i) that the patients they see have complex health and social problems; (ii) that their work hours are unpredictable; and (iii) that their partners/spouses have good employment opportunities in their location of work. Also included is a variable that measures the opportunity for social interaction in doctors' location of work on a three-point scale (very limited, average and very good). To capture the effect of after-hours work and on-call on earnings, a binary variable on whether doctors do after-hours work and on-call is included.

\subsection{Local area characteristics}

Advantages and disadvantages of jobs also include the characteristics of the local area of work (Elliot et al., 2007). The MABEL survey was linked to a dataset of local area characteristics. This included a standardised GP: population ratio measured at the level of the Statistical Local Area in which GPs work to capture the effect of competition and patients' access to health care on earnings. As earnings also may be influenced by the socioeconomic status of patients in the area, the 2006 Index of Relative Socio-economic Advantage and Disadvantage in deciles in GPs' work location also is included (Australian Bureau of Statistics, 2008). To capture factors such as the cost of living, we included 2008 median house prices in the postcodes of doctors' area of residence. We also included state and territory binary variables as well as a three-category measure (major city, inner regional and other) of remoteness based on the Australian Standard Geographic Classification (Australian Bureau of Statistics, 2003). The latter captures the higher cost of practicing in a rural or remote area.

\subsection{Decomposition analysis of GP and specialists earnings}

Differences in earnings have been shown to be important in influencing doctors' choice of specialty (Hurley 1991; Thornton 2000; Nicholson 2002) and the choice to become specialist rather than GP in particular (Rosenblatt and Andrilla 2005; Bodenheimer et al.; 2007). The differences in the mean earnings of GPs and specialists arise because of differences in the characteristics of doctors in each group (e.g. working hours, gender, experience and job attributes) as well as differences in the returns to these characteristics. The market returns to these characteristics also are referred to as unobservable or unexplained factors. We employ the standard Oaxaca-Blinder decomposition approach (Blinder 1973; Oaxaca 1973) to investigate these issues. Following the notation in Fortin et al. (2010), the mean log income gap of specialists and GPs may be decomposed as follows:

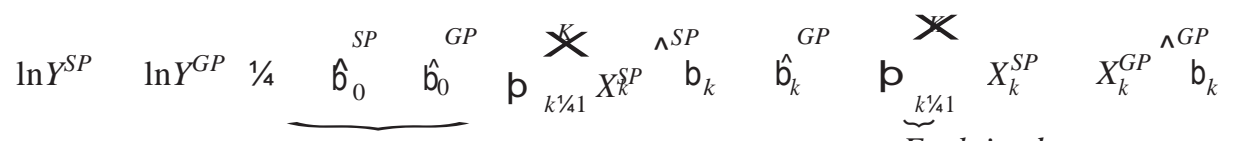

\footnotetext{
where $\hat{\mathrm{b}}_{0}^{j}$ and $\hat{\mathrm{b}}_{k}^{j}(j=G P, S P ; k=1, \ldots, K)$ denote intercept and slope coefficients from the two separate earnings regression models. The first part on the right-hand side is the 'unexplained' component, which contains two
} 
terms. The first term is the difference in intercepts. This is part of the unexplained component that is due to 'group membership' (Jones and Kelly 1984). The second term is the part of the earnings gap that is explained by differences in the returns to the characteristics of GPs and specialists. The second part on the right-hand side is referred to as the 'explained' effect directly because of differences in the characteristics of GPs and specialists.

In the standard Oaxaca-Blinder decomposition approach, the difference in intercepts $\hat{b}_{0}^{S P} \hat{b}_{0}^{G P}$ is considered as part of the 'unexplained effect'. Following Gravelle and Hole (2008), we estimate the contribution to the income gap arising from the difference in intercepts separately from the contribution because of differences in returns to characteristics. This allows us to more accurately measure the size of the two effects and assess their relative contributions to explaining the income gap. In addition to an aggregate decomposition of the income gap into the three components described above, we undertake a detailed decomposition in which we measure the contribution of each $k^{\text {th }}$ covariate to the explained and unexplained components. This is given

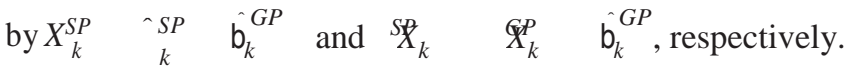

We used explanatory variables that are common to both GPs and specialists in the analysis. As a result, employment types and work settings categories for specialists were aggregated into a binary indicator selfemployment, and variables, such as GP practice size, work visa, GP density and specialty types, have been excluded. In the presence of categorical regressors, it is well known that the magnitude of the unexplained part of the decomposition depends on the choice of the omitted or base category (Jones, 1983; Jones and Kelly, 1984; Oaxaca and Ransom, 1999). This is because one cannot distinguish the part of the decomposition that is attributed to the differences in intercepts from the part attributed to differences in the coefficient of the omitted category. We employ the solution proposed by Yun (2005), which involves normalising the coefficients on categorical variables prior to the decomposition. This approach is equivalent to averaging the estimates obtained from a series of decompositions, with all possible categories as the reference group.

The decomposition as defined in Equation (1) uses the GP coefficients as counterfactuals. The decomposition therefore tells us how the average earnings of GPs would change if they had the same characteristics, and returns to characteristics, as specialists. We test the sensitivity of the decomposition results by considering the case where specialist coefficients are used as counterfactuals. This is akin to writing the decomposition as follows:

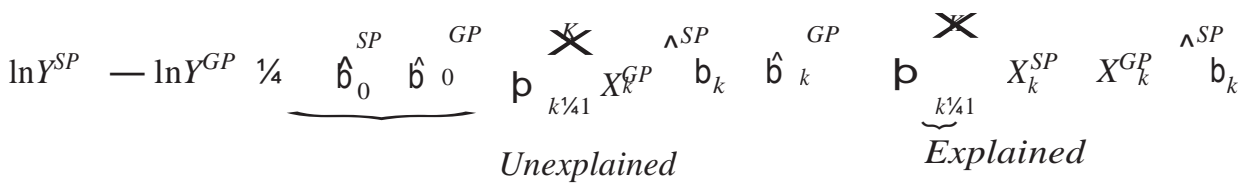

The standard errors of the decomposition components are calculated using the delta method as proposed by Jann (2008).

\section{RESULTS}

\subsection{Descriptive statistics and the analysis sample}

Table I presents the summary statistics of variables described in Section 3. The means (and SDs) of annual T1 gross personal earnings of GPs and specialists were \$181 587 (\$110 988) and \$333 108 (\$237 390), respectively. The mean annual hours worked was 2039.2 (777.7) for GPs and 2333.5 (728.6) for specialists. The mean weekly hours worked for GPs and specialists are 39.4 (14.8) and 45.1 (13.8) hours, and hourly earnings are $\$ 89.3$ (42.7) and $\$ 145.5$ (104.8). Both GPs and specialists worked on average of 51.6 weeks per year (including any annual and sick leave). About $44.9 \%$ of GPs and $27.6 \%$ of specialists were female; $48.9 \%$ of GPs and $45.7 \%$ of specialists were self-employed. Anaesthetics (15\%) and psychiatry (11\%) are the two largest specialty groups. The majority of GPs $(70.2 \%)$ and specialists $(83.9 \%)$ were located in major cities.

For our analysis sample, observations were excluded if there were missing data on either the earnings, hours or any of the independent variables. In the full sample of 3906 GPs and 4597 specialists, $16.4 \%$ of GPs and 
Table I. Descriptive statistics of variables

\begin{tabular}{|c|c|c|c|c|}
\hline \multirow[b]{2}{*}{ Variable } & \multicolumn{2}{|c|}{ GPs $(n=2013)$} & \multicolumn{2}{|c|}{ Specialists $(n=2634)$} \\
\hline & Mean & SD & Mean & SD. \\
\hline Annual gross earnings (\$) & 181587 & 110988 & 333108 & 237390 \\
\hline Annual hours & 2039.2 & 777.7 & 2333.5 & 728.6 \\
\hline $\begin{array}{l}\text { Female }(\%) \\
\text { Have child under } 5 \text { years }(\%)\end{array}$ & $\begin{array}{r}44.9 \\
0.16\end{array}$ & & $\begin{array}{r}27.6 \\
0.22\end{array}$ & \\
\hline Australian medical school (\%) & 79.5 & & 83.6 & \\
\hline Fellowship (\%) & 60.0 & & 96.4 & \\
\hline $\begin{array}{l}\text { Number of postgraduate qualifications } \\
\text { Temporary visa }(\%)\end{array}$ & $\begin{array}{l}0.57 \\
0.021\end{array}$ & 0.77 & 0.26 & 0.55 \\
\hline Experience: $<10$ years $(\%)$ & 7.9 & & 2.0 & \\
\hline Experience: $10-19$ years $(\%)$ & 23.6 & & 30.4 & \\
\hline $\begin{array}{l}\text { Experience: } 20-29 \text { years }(\%) \\
\text { Experience: } 30-39 \text { years }(\%)\end{array}$ & 38.6 & & 35.5 & \\
\hline Experience: $\geq 40$ years $(\%)$ & 6.9 & & 9.2 & \\
\hline Hospital work $(\%)$ & 0.23 & & & \\
\hline $\begin{array}{l}\text { \% time in clinical work } \\
\text { Self-employed GPs }(\%)\end{array}$ & 48.9 & & 77.3 & 22.8 \\
\hline Self-employed hospital specialists (\%) & & & 16.4 & \\
\hline Self-employed non-hospital specialists (\%) & & & 29.3 & \\
\hline $\begin{array}{l}\text { Hospital specialist: fixed payments }(\%) \\
\text { Hospital specialist: salaried no RPP }(\%)\end{array}$ & & & 2.9 & \\
\hline Hospital specialist: salaried with $R P P(\%)$ & & & 27.2 & \\
\hline Non-hospital specialist: contract $(\%)$ & & & 3.6 & \\
\hline $\begin{array}{l}\text { Non-hospital specialist: salary (\%) } \\
\text { Hospital/non-hospital specialist: other }\end{array}$ & & & $\begin{array}{l}5.6 \\
0.60\end{array}$ & \\
\hline GP practice size: solo $(\%)$ & 7.4 & & & \\
\hline GP practice size: $2-3$ doctors $(\%)$ & 19.8 & & & \\
\hline $\begin{array}{l}\text { GP practice size: } 4-5 \text { doctors }(\%) \\
\text { GP practice size: } 6-9 \text { doctors }(\%)\end{array}$ & 22.2 & & & \\
\hline GP practice size: $\geq 10$ doctors $(\%)$ & 16.8 & & & \\
\hline Do after-hour and on-call work $(\%)$ & 52.0 & & 81.0 & \\
\hline $\begin{array}{l}\text { Patients have complex health/social problems (\%) } \\
\text { Unpredictable work hours }(\%)\end{array}$ & $\begin{array}{l}67.7 \\
26.8\end{array}$ & & $\begin{array}{l}60.9 \\
40.5\end{array}$ & \\
\hline Limited opportunity for social interaction (\%) & 0.10 & & 0.17 & \\
\hline $\begin{array}{l}\text { Good employment opportunity for partner }(\%) \\
\text { Cardiology }(\%)\end{array}$ & 0.56 & & $\begin{array}{l}0.54 \\
0.016\end{array}$ & \\
\hline Paediatric medicine $(\%)$ & & & 0.060 & \\
\hline Gastroenterology $(\%)$ & & & 0.021 & \\
\hline $\begin{array}{l}\text { General medicine }(\%) \\
\text { Internal medicine-other }(\%)\end{array}$ & & & $\begin{array}{l}0.028 \\
0.132\end{array}$ & \\
\hline Thoracic medicine $(\%)$ & & & 0.018 & \\
\hline Intensive care-internal medicine (\%) & & & 0.016 & \\
\hline $\begin{array}{l}\text { Pathology }(\%) \\
\text { General surgery }(\%)\end{array}$ & & & $\begin{array}{l}0.04 \\
0.045\end{array}$ & \\
\hline Orthopaedic surgery (\%) & & & 0.032 & \\
\hline Surgery: other $(\%)$ & & & 0.052 & \\
\hline $\begin{array}{l}\text { Anaesthesia (\%) } \\
\text { Diagnostic radiology (\%) }\end{array}$ & & & $\begin{array}{l}0.15 \\
0.047\end{array}$ & \\
\hline Emergency medicine (\%) & & & 0.053 & \\
\hline Psychiatry $(\%)$ & & & 0.11 & \\
\hline $\begin{array}{l}\text { Obstetrics/gynaecology }(\%) \\
\text { Ophthalmology }(\%)\end{array}$ & & & $\begin{array}{l}0.057 \\
0.028\end{array}$ & \\
\hline Specialty: other $(\%)$ & & & 0.093 & \\
\hline ASGC: major city (\%) & 70.2 & & 83.9 & \\
\hline $\begin{array}{l}\text { ASGC: inner regional (\%) } \\
\text { ASGC: other }(\%)\end{array}$ & $\begin{array}{l}17.3 \\
12.5\end{array}$ & & 12.7 & \\
\hline Standardised GP density & 0.52 & 1.16 & & \\
\hline SEIFA & 7.09 & 2.59 & & \\
\hline Log of median house price & 13.1 & 0.54 & 13.37 & 0.53 \\
\hline
\end{tabular}

ASGC, Australian Standard Geographic Classification; GP, general practitioner; RPP, rights to private practice. 
$19.9 \%$ of specialists have missing data on gross personal earnings. Doctors who reported working less than 4 hours or more than 100 hours per week were excluded from the analysis. ${ }^{2}$ In addition, observations were excluded where the sum of reported hours across the different work settings did not equal the reported total hours and where the number of weeks worked per year was less than 26 . The number of observations available for analysis is 2013 GPs and 2634 specialists.

We analyse the factors that are associated with non-response to the gross personal earnings question asked in the survey using separate probit regressions for GPs and specialists. The outcome variable of interest is a binary variable, which assumes the value of 1 if information on gross personal earnings is missing. The results are presented in Appendix Table AI. A key finding in the literature on item non-response is that higher income individuals are more likely not to divulge information on their income (Lillard et al., 1986; Riphahn and Serfling 2005). If this is the case, we expect that the probability of response to the income question is lower for doctors who have more years of experience and/or who are self-employed. There is weak evidence that the probability of item non-response is associated with income, given that the marginal effects on the experience and selfemployment variables are positive, although most of the estimates are not statistically significant.

\subsection{Endogeneity of hours}

The endogeneity of the hours variable in both the GP and specialist earnings equations was tested with 2SLS regressions using a binary variable indicating whether the respondent has children under the age of 5 years as an instrument. We also estimated 2SLS regressions for GPs and specialists using a set of binary variables indicating whether respondents were living with a partner (or spouse) and the partner's employment status in combination with the 'child under 5' variable, but this set of instruments failed the over-identification test. We tested subsets of these instruments using the 'difference-in-Sargan' statistics (see Hayashi, 2000: pp. 218-21), and the $C$ statistics indicate that the partner and partner's employment status variables are not valid instruments. Hence, we used only the 'child under 5' binary variable as an instrument in both regressions. We also explored different variables that capture the presence of children (e.g. number of dependent children), but the 'child under 5' binary variable produces the most robust result.

The instrument was significant in the first-stage regression of both the GP $(F=65.82, p>F=0.0000)$ and specialist $(F=35.64, p>F=0.0000)$ models. The endogeneity of the hours variable was examined using the Hausman test (Baum et al., 2003). In the GP regression, the test result rejected the null hypothesis that the hours variable is exogenous $\left(\mathrm{w}^{2}=10.94, p<0.001\right)$. However, in the specialist regression, the null hypothesis could not be rejected $\left(w^{2}=1.88, p=0.170\right)$. For consistency in the exposition of the results, we present the 2SLS estimates for both the GP and specialist regressions.

\subsection{General practitioners}

The results from the 2SLS regression of log annual gross earnings for GPs are presented in columns 2 and 3 in Table II. The coefficient on $\log$ annual hours worked for GPs is significantly less than one $(F=17.69$, T2 $p>F=0.0000$ ), which suggests that earnings are not proportional to hours worked. This suggests that for every $1 \%$ increase in hours worked, earnings increase by $0.45 \%$. This result is consistent with Gravelle and Hole (2008) who found that $1 \%$ increase in hours worked leads to a $0.25 \%$ and $0.56 \%$ increase in earnings for male and female GPs, respectively.

Female GPs earned, on average, $24.9 \%$ less than male GPs. ${ }^{3}$ The earnings of GPs who completed their basic medical degree in Australia are $7.1 \%$ lower than those who completed their medical degree overseas. Neither

\footnotetext{
${ }^{2}$ The lower bound on weekly working hours is stipulated at 4 hours as it corresponds to the typical length of a work session (e.g. voluntary medical officers in hospitals). The choice in the upper bound of 100 was informed by an Australia Medial Association report on safe working hours where senior doctors (i.e. hospital specialists) were found to work a maximum of 92-96 hours per week (Australian Medical Association 2006).

${ }^{3}$ This is calculated by computing (exp(coefficient $\left.)-1\right) * 100=(\exp (0.286)-1) * 100=24.87 \%$.
} 
Table II. Two-stage least squares earnings regression for general practitioners and specialists

\begin{tabular}{|c|c|c|c|c|}
\hline \multirow[b]{2}{*}{ Variable } & \multicolumn{2}{|c|}{ GPs } & \multicolumn{2}{|c|}{ Specialists } \\
\hline & Coefficient & $t$-statistics ${ }^{\mathrm{a}}$ & Coefficient & $t$-statistics ${ }^{\mathrm{a}}$ \\
\hline Log annual hours & $0.450 * * *$ & 3.44 & $0.465 * *$ & 2.53 \\
\hline Female & $0.286^{* * * *}$ & 7.31 & $0.241 * * *$ & 4.51 \\
\hline Australian medical school & $0.074 * * *$ & 2.69 & 0.018 & 0.67 \\
\hline Fellowship & 0.016 & 0.64 & 0.064 & 1.34 \\
\hline Number of postgraduate qualifications. & 0.0030 & 0.23 & 0.011 & 0.65 \\
\hline Temporary visa & 0.110 & 1.50 & & \\
\hline \multicolumn{5}{|c|}{$\begin{array}{l}\text { Experience (reference is }<10 \text { years for GPs and }<15 \text { years } \\
\text { for specialists) }\end{array}$} \\
\hline $10-19$ years $(15-19$ for $s p e c)$ & 0.046 & 0.95 & $0.136 * * *$ & 4.07 \\
\hline 20-29years & 0.026 & 0.73 & $0.152 * * *$ & 4.08 \\
\hline $30-39$ years & 0.0049 & 0.12 & $0.122 * * *$ & 2.79 \\
\hline$\geq 40$ years & $0.213^{* * *}$ & 2.93 & $0.136^{* * *}$ & 2.74 \\
\hline Hospital work & 0.028 & 0.96 & & \\
\hline$\%$ time in clinical work & & & $0.0022 * * *$ & 3.35 \\
\hline $\begin{array}{l}\text { Self-employed GPs } \\
\text { GP Practice Size (reference is solo practice) }\end{array}$ & $0.244 * * *$ & 7.41 & & \\
\hline $2-3$ doctors & 0.069 & 1.35 & & \\
\hline $4-5$ doctors & 0.079 & 1.61 & & \\
\hline 6-9 doctors & $0.081 *$ & 1.72 & & \\
\hline$\geq 10$ doctors & $0.137 * * *$ & 2.88 & & \\
\hline \multicolumn{5}{|c|}{ Employment type (reference is Empl. hosp. spec: Salary without RPP) } \\
\hline Self-employed hospital specialists. & & & $0.247 * * *$ & 5.81 \\
\hline $\begin{array}{l}\text { Self-employed non-hospital specialists. } \\
\text { Hospital specialist: fixed payments }\end{array}$ & & & $\begin{array}{l}0.272 * * * \\
0.103\end{array}$ & 1.55 \\
\hline Hospital specialist: salaried no $R P P$ & & & 0.043 & 1.59 \\
\hline Hospital specialist: salaried with $R P P$ & & & 0.052 & 0.60 \\
\hline $\begin{array}{l}\text { Non-hospital specialist: contract } \\
\text { Non-hospital specialist: salary }\end{array}$ & & & $\begin{array}{l}0.086 \\
0.010\end{array}$ & 0.23 \\
\hline Hospital/non-hospital specialist: Other & & & 0.156 & 1.51 \\
\hline \multicolumn{5}{|l|}{ Specialty type (reference is paediatric medicine) } \\
\hline $\begin{array}{l}\text { Cardiology } \\
\text { Gastroenterology }\end{array}$ & & & $\begin{array}{l}0.293 * * * \\
0.276 * * *\end{array}$ & $\begin{array}{l}2.62 \\
3.83\end{array}$ \\
\hline General medicine & & & $0.104 * *$ & 1.49 \\
\hline $\begin{array}{l}\text { Intensive care-internal medicine } \\
\text { Thoracic medicine }\end{array}$ & & & $\begin{array}{l}0.454 * * * * \\
0.055\end{array}$ & $\begin{array}{l}5.64 \\
0.81\end{array}$ \\
\hline Int. med: other & & & $0.112 * * *$ & 2.66 \\
\hline Pathology & & & $0.361 * * *$ & 7.30 \\
\hline $\begin{array}{l}\text { General surgery } \\
\text { Orthopaedic surgery }\end{array}$ & & & $\begin{array}{l}0.383 * * * \\
0.599 * * *\end{array}$ & 6.31 \\
\hline Surgery: other & & & $0.483 * * *$ & 7.34 \\
\hline Anaesthesia & & & $0.393 * * *$ & 9.34 \\
\hline $\begin{array}{l}\text { Diagnostic radiology } \\
\text { Emergency medicine }\end{array}$ & & & $\begin{array}{l}0.601 * * * \\
0.219 * * *\end{array}$ & $\begin{array}{r}10.81 \\
4.95\end{array}$ \\
\hline Obstetrics/gynaecology & & & $0.533 * * *$ & 9.39 \\
\hline Ophthalmology & & & $0.401 * * *$ & 5.81 \\
\hline $\begin{array}{l}\text { Psychiatry } \\
\text { Other }\end{array}$ & & & $\begin{array}{l}0.093 * * * \\
0.246 * * *\end{array}$ & $\begin{array}{l}2.57 \\
5.29\end{array}$ \\
\hline Do after-hour and on-call work & $0.076^{* *}$ & 2.55 & $0.214 * * *$ & 4.05 \\
\hline Patients have complex health/social problems & 0.0089 & 0.34 & $0.107 * * *$ & 4.92 \\
\hline Unpredictable work hours & 0.044 & 1.44 & $0.055^{*}$ & 1.70 \\
\hline $\begin{array}{l}\text { Limited opportunity for social interaction } \\
\text { Good employment opportunity for partner }\end{array}$ & $\begin{array}{l}0.015 \\
0.023\end{array}$ & $\begin{array}{l}0.44 \\
1.02\end{array}$ & 0.024 & 0.98 \\
\hline \multicolumn{5}{|l|}{ State of work (reference is NSW) } \\
\hline $\begin{array}{l}\text { VIC } \\
\text { QLD }\end{array}$ & $\begin{array}{l}0.0085 \\
0.050\end{array}$ & $\begin{array}{l}0.31 \\
1.48\end{array}$ & $\begin{array}{l}0.026 \\
0.145^{* * * *}\end{array}$ & 0.85 .30 \\
\hline SA & 0.012 & 0.30 & 0.0031 & 0.090 \\
\hline WA & $0.084^{* *}$ & 2.21 & $0.084 * * *$ & 2.77 \\
\hline
\end{tabular}


Table II. (continued)

\begin{tabular}{|c|c|c|c|c|}
\hline \multirow[b]{2}{*}{ Variable } & \multicolumn{2}{|c|}{ GPs } & \multicolumn{2}{|c|}{ Specialists } \\
\hline & Coefficient & $t$-statistics ${ }^{\mathrm{a}}$ & Coefficient & $t$-statistics ${ }^{\mathrm{a}}$ \\
\hline TAS & $0.155^{* *}$ & 2.56 & $0.125^{*}$ & 1.84 \\
\hline $\mathrm{ACT}$ & 0.040 & 0.52 & 0.015 & 0.18 \\
\hline NT & 0.065 & 0.75 & 0.024 & 0.31 \\
\hline \multicolumn{5}{|l|}{$A S G C$ (reference is major city) } \\
\hline Inner regional & 0.0009 & 0.28 & 0.041 & 1.03 \\
\hline Other & $0.110^{* * *}$ & 2.88 & 0.016 & 0.27 \\
\hline Standardised GP density & $8.023 * *$ & 2.172 & & \\
\hline Log of median house price & 0.044 & 1.64 & $0.049 * *$ & 1.99 \\
\hline $\begin{array}{l}\text { Constant } \\
n\end{array}$ & $2013^{7.996^{* * * *}}$ & 8.14 & $2634^{7.459^{* * * *}}$ & 5.17 \\
\hline$R^{2}$ & \multicolumn{2}{|l|}{0.515} & \multicolumn{2}{|l|}{0.523} \\
\hline $\begin{array}{l}F \text { test on excluded instrument (child under } 5 \text { variable) } \\
w^{2} \text { statistics on the null hypothesis that log hours is exogenous }\end{array}$ & \multicolumn{2}{|c|}{$\begin{aligned} F & =65.82(p>F=0.0000) \\
W^{2} & =10.94(p<0.001)\end{aligned}$} & \multicolumn{2}{|c|}{$\begin{array}{l}F=35.64(p>\mathrm{F}=0.0000) \\
\mathrm{w}^{2}=1.88(p=0.170)\end{array}$} \\
\hline Wald test on null hypothesis that coefficient on log hours is unity & \multicolumn{2}{|c|}{$F=17.69(p>F=0.0000)$} & \multicolumn{2}{|c|}{$F=8.49(p>F=0.0038)$} \\
\hline
\end{tabular}

fellowship status (i.e. fellowship of the Royal Australia College of General Practitioners) nor the number of other postgraduate qualifications is significantly associated with earnings. The earnings of GPs who are on temporary work visas and are required to work in regions experiencing medical workforce shortages are not different from GPs who do not face such constraints in their location of practice. The coefficients on the experience variables suggest a slightly positive gradient, which reaches a peak at 20-29 years of experience, but this relationship is not statistically significant. However, the earnings of GPs with 40 or more years of experience is $19.1 \%$ lower than those of GPs with less than 10 years of experience.

Self-employed GPs earned, on average, $27.6 \%$ more than GPs who are salaried or on contracts. This is expected as the earnings of self-employed GPs reflect returns on managerial responsibilities and capital investments made to the practice. GPs working in larger practices earn significantly more than solo practitioners where the magnitude of this difference is largest for practices with 10 or more doctors. This is according to expectation, given that the size of the medical practice affects the doctor's operating costs as doctors in larger practices can share the cost of capital equipment and administrative overheads.

For the self-reported job characteristics, GPs who undertake after-hours and/or on-call work earn 7.9\% more than those who do not. Earnings are not associated with the doctor's opinion on whether their work hours are unpredictable, with the complexity of patients' health and social problems, or whether the practice location restricts opportunities for social interactions.

Earnings do not vary significantly by state of work except for GPs in Western Australia and Tasmania compared with their counterparts in New South Wales. The earnings of GPs who practice in outer regional, rural and remote Australia are 11.6\% higher than those of GPs working in major cities. Earnings are lower for GPs who work in areas that are socio-economically more advantageous and where there is a higher concentration in the number of GPs relative to the size of the population. Finally, earnings are positively associated with the residential house prices in GP's location of residence, but significance is just below the $10 \%$ level.

\subsection{Specialists}

The results from the 2SLS regression of log annual earnings for specialists are presented in columns 4 and 5 in Table II. The estimate of the coefficient on log hours is 0.47 , which is again significantly lower than one 
$(F=8.49, p>F=0.0038)$, which indicates that earnings are not proportional to hours worked. Female specialists earned, on average, $21.4 \%$ less than their male colleagues. Specialists' earnings are not associated with fellowship qualification or the number of postgraduate qualifications. Earnings are increasing in the number of years of experience, with the earnings-experience profile reaching the maximum at 20-29years of experience. Specialists who devote more of their time to clinical work earned slightly more than those who undertake proportionally more non-clinical work such as administration, management and education activities.

The income of specialists varies significantly with employment type and work settings. Compared with hospital-based salaried specialists with no RPP, the annual earnings of self-employed hospital-based and non-hospital-based specialists are approximately $28 \%-31 \%$ higher. As with the case of GPs, this reflects returns to entrepreneurship and risk bearing by those who are self-employed as business owners, independent contractors or solo practitioners. The coefficient on the binary variable denoting salaried specialists with RPP is positive, which is as expected, given that specialists on these contracts typically either receive an additional private practice allowance on top of their salary or retain a portion of their earnings generated through private practice in public hospitals. However, the estimate is not statistically significant. Overall, the income of employed specialists does not vary much across the different types of employment contracts.

The income of specialists varies considerably by the field of specialty. Earnings are the highest for diagnostic radiologists, followed by orthopaedic surgeons, other surgeons (other than general or orthopaedic), obstetricians and gynaecologists, intensive care specialists, anaesthetists, ophthalmologists, pathologists, general surgeons, gastroenterologists, emergency medicine physicians, cardiologists, internal medicine specialists (other-e.g. geriatrics, endocrinology and medical oncology), general medicine specialists, psychiatrists, and finally, paediatricians and thoracic medicine specialists.

The results also indicate that earnings vary by doctors' job characteristics and work environment. Specialists who undertake after-hours and/or on-call work earned about $23.9 \%$ more than those who do not. Earnings are approximately $10.1 \%$ lower for specialists who indicated that their patients have complex health and social problems. Specialists who practice in geographic locations, which provide good employment opportunities for their partners earned comparatively more than those who indicated otherwise.

The remuneration of medical specialists varies significantly across states and territories. Compared with specialists who are based in New South Wales (NSW), specialists from Western Australia and Queensland earned about $8.8 \%$ and $15.6 \%$ more, respectively. As in the case for GPs, the earnings of specialists in Tasmania are about $11.8 \%$ lower compared with their NSW counterparts. Specialists earnings do not vary significantly by geographic remoteness of specialists' work locations, but earnings are higher in residential areas where median house prices are higher.

\subsection{Decomposition analysis}

The mean annual income (log income) of GPs and specialists were \$181 588 (11.923) and \$333 108 (12.512), respectively, corresponding to a mean income (log income) differential of $\$ 151520(0.589)$. The results of the aggregate decomposition are reported at the top of Table III, followed by the results from the detailed decom- T3 position. The results from the aggregate decomposition indicate that the largest proportion of the log income differential stems from the differences in the constants and from the differences in the returns to characteristics. Overall, the decomposition results are sensitive to the choice of the counterfactual - the explained component is larger when specialist coefficients are used as the counterfactual (42.3\% versus $22.1 \%)$. This is attributed to differences in the contributions from the number of postgraduate qualifications, experience, after-hours and on-call work, complexity of patients and unpredictable work hours. The change in the size of the explained component is, to a large degree, influenced by higher returns on experience and after-hours and on-call work for specialists compared with GPs.

The results from the detailed decomposition reveal the extent to which the differences in specific observable characteristics and the returns on these characteristics explain the income gap. The mean income of GPs is lower than that of specialists because GPs work fewer hours, are more likely to be female and are less likely to undertake 
Table III. Decomposition of differences in log income between GPs and specialists

\begin{tabular}{|c|c|c|c|c|c|c|}
\hline & \multicolumn{3}{|c|}{ (1) } & \multicolumn{3}{|c|}{ (2) } \\
\hline & \multicolumn{3}{|c|}{ GP coefficients as counterfactual } & \multicolumn{3}{|c|}{$\underline{\text { Specialist coefficients as counterfactual }}$} \\
\hline & Coefficient & $t$-statistics & $\%$ & Coefficient & $t$-statistics & $\%$ \\
\hline Difference in log income & $0.589 * * *$ & 32.62 & 100.00 & $0.589 * * *$ & 32.62 & 100.00 \\
\hline \multicolumn{7}{|c|}{ Aggregate decomposition } \\
\hline $\begin{array}{l}\text { Differences because of } \\
\text { Characteristics (Explained) }\end{array}$ & $0.130 * * *$ & 6.62 & 22.1 & & 9.61 & \\
\hline Coefficients + constants (Unexplained) & $0.459 * * *$ & 21.23 & $\begin{array}{l}22.1 \\
77.9\end{array}$ & $0.340 * * *$ & $\begin{array}{r}9.01 \\
12.86\end{array}$ & $\begin{array}{l}42.3 \\
57.7\end{array}$ \\
\hline Coefficients & 0.150 & 0.08 & 25.5 & 0.030 & 0.02 & 5.1 \\
\hline Constant & 0.310 & 0.17 & 52.6 & 0.310 & 0.17 & 52.6 \\
\hline \multicolumn{7}{|c|}{ Detailed decomposition } \\
\hline $\begin{array}{l}\text { Differences in characteristics } \\
\text { Log annual hours }\end{array}$ & $0.077 * * *$ & 3.67 & 13.1 & $0.063 *$ & 1.88 & 10.7 \\
\hline Female & $0.050^{* * *}$ & 6.05 & 8.5 & $0.053 * * *$ & 4.67 & 9.0 \\
\hline Australian medical school & $0.0027 * *$ & 2.02 & 0.5 & 0.0011 & 0.95 & 0.2 \\
\hline $\begin{array}{l}\text { Fellowship } \\
\text { Number of postgraduate qualification }\end{array}$ & $\begin{array}{l}0.0048 \\
0.0012\end{array}$ & 0.28 & $0.2^{0.8}$ & $\begin{array}{l}0.0018 \\
0.015^{* * *}\end{array}$ & $\begin{array}{l}0.09 \\
2.76\end{array}$ & 0.3 \\
\hline Temporary visa & 0.0015 & 1.31 & 0.3 & 0.00078 & 0.50 & 0.1 \\
\hline Experience & 0.0011 & 0.506 & 0.2 & 0.0064 & 1.51 & 1.1 \\
\hline Self-employed & $0.0072 * *$ & 2.06 & 1.2 & $0.0097 * *$ & 2.13 & 1.6 \\
\hline Do after-hour and on-call work & $0.025^{* * *}$ & 2.91 & 4.2 & $0.068^{* * *}$ & 4.41 & 11.5 \\
\hline Patients have complex health/social problems & 0.00084 & 0.51 & 0.1 & $0.017 * * *$ & 4.45 & 2.9 \\
\hline Unpredictable work hours & $0.0073 *$ & 1.76 & 1.2 & $0.015^{* * *}$ & 3.15 & 2.5 \\
\hline Limited opportunity for social interaction & 0.00042 & 0.20 & 0.1 & 0.00080 & 0.47 & 0.1 \\
\hline Good employment opportunity for partner & 0.00050 & 0.86 & 0.1 & 0.00031 & 0.69 & 0.1 \\
\hline State $^{\mathrm{a}}$ & 0.00071 & 0.32 & 0.1 & 0.0044 & 1.60 & 0.7 \\
\hline Remoteness $^{\mathrm{a}}$ & $0.0096^{* *}$ & 2.10 & 1.6 & 0.0072 & 1.15 & 1.2 \\
\hline Log annual hours & 0.67 & 0.37 & 113.8 & 0.65 & 0.37 & 110.4 \\
\hline Female & 0.0039 & 0.24 & 0.7 & 0.00089 & 0.24 & 0.2 \\
\hline Australian medical school & 0.013 & 1.06 & 2.2 & 0.012 & 1.05 & 2.0 \\
\hline Number of postgraduate qualification & $0.013^{* *}$ & 2.37 & 2.2 & $0.030 * *$ & 2.38 & 5.1 \\
\hline Temporary visa & 0.026 & 0.37 & 4.4 & 0.025 & 0.37 & 4.2 \\
\hline Experience & $0.35 * * *$ & 2.81 & 59.4 & $0.34 * * *$ & 2.81 & 57.7 \\
\hline Self-employed & $0.0033^{*}$ & 1.83 & 0.6 & 0.00083 & 0.87 & 0.1 \\
\hline Do after-hour and on-call work & $0.046^{* *}$ & 2.46 & 7.8 & 0.0030 & 1.46 & 0.5 \\
\hline Patients have complex health/social problems & $0.026^{* * * *}$ & 6.30 & 4.4 & $0.042 * * *$ & 6.89 & 7.1 \\
\hline Unpredictable work hours & $0.015 * * *$ & 3.43 & 2.5 & $0.037 * * *$ & 3.61 & 6.3 \\
\hline Limited opportunity for social interaction & 0.0068 & 0.459 & 1.2 & 0.0080 & 0.46 & 1.4 \\
\hline Good employment opportunity for partner & 0.0017 & 1.32 & 0.3 & 0.0025 & 1.35 & 0.4 \\
\hline State $^{\mathrm{a}}$ & 0.0010 & 0.039 & 0.2 & 0.0062 & 0.25 & 1.1 \\
\hline Remoteness $^{\mathrm{a}}$ & 0.00366 & 0.17 & 0.6 & 0.0013 & 0.067 & 0.2 \\
\hline
\end{tabular}

Contributions may not add up exactly because of rounding.

${ }^{a}$ For categorical covariates, the contributions of the included and omitted dummy variables are aggregated over the following categories: state $=($ NSW, VIC, QLD, SA, WA, TAS, ACT, NT); remoteness $=($ major city, inner regional, other $)$. For binary covariates, the contributions of the included and omitted variables are aggregated over their respective categories (e.g. gender = female, male).

after-hours and on-call work. It also is clear that the experience of GPs is valued less in the market compared with specialists and that GPs have a lower return on after-hours and on-call work. In addition to the above, the earnings differential also is more broadly explained by differences in the proportion of, and returns to, selfemployment; the number of postgraduate qualifications; and differences in the returns to work characteristics such as the complexity of patients' health and social problems and the unpredictability of work hours. 


\section{DISCUSSION OF RESULTS AND POLICY IMPLICATIONS}

This paper is the first to examine the determinants of earnings of GPs and specialists in Australia and to examine the sources of the differences in earnings between GPs and specialists. Our results show that doctors' earnings are associated with gender, experience, the size of the GP practice, employment type, specialty and the characteristics of doctors' location of work.

Some interesting observations arise from our results. Our results show that the earnings of female GPs and specialists are roughly $17 \%-23 \%$ lower than those of male doctors. This finding is in agreement with Bashaw and Heywood (2001) who found that the annual earnings of female doctors are 20\%-22\% lower than those of male doctors in USA. In Gravelle and Hole (2008), the difference in annual earnings of male and female GPs in the UK is $38.3 \% .^{4}$ Although an examination of earnings differentials should ideally be based on a decomposition approach (see Oaxaca, 1973), our results provide cursory evidence that gender differences in earnings exist for doctors in Australia. Second, the results show significant differences in earnings by employment type. For GPs and specialists, the earnings of self-employed doctors are 25\%-26\% higher than those of employed doctors, with these returns being higher for specialists. The earnings of self-employed doctors can be separated into two components: the returns to labour inputs as well as the returns to ownership of practice. Headen (1990) estimated the value of the return on entrepreneurship and found that this accounts for $16.2 \%$ of net income for self-employed US physicians in general/family practice or internal medicine. This estimate would be the difference between the earnings of self-employed and employed doctors if one would hold constant the returns to labour inputs across the two employment types. Third, our results indicate that the earnings of GPs in larger practices are higher compared with those of solo practitioners. Morris et al. (2010) showed that UK GPs in solo practice worked longer hours and had the highest annual net incomes ${ }^{5}$ but found no difference in the hourly wages by practice size. In Australia, large practices may be more likely to be owned by large commercial companies relative to large practices in the UK.

Finally, we observe significant variation in remuneration across the different specialties. These variations are likely to arise from differences in the cost and length of the requisite training in each specialty, the complexity of skills required, the market conditions for specialist services, and historical relativities in the MBS. ${ }^{6}$

The decomposition analysis examined the sources of the differences in earnings between GPs and specialists. Differences in observable characteristics (proportion female, hours worked, self-employment, on call) explained between $22 \%$ and $42 \%$ of the difference in log income. Differences in the returns to characteristics explained between $5 \%$ and $26 \%$ of the difference in earnings, including differences in the returns to experience, having postgraduate qualifications, and having patients with complex health and social problems. Unobservable factors captured in the constant terms explained almost 53\% of the difference in log income between GPs and specialists. This is likely to include unmeasured skills and ability as well as status and reputational effects that are more highly valued in the market for specialists than for GPs. The unobserved component of the difference also may reflect the historic bias in the Medicare Fee Schedule that provides specialists with higher incomes compared with GPs. Previous research has shown a number of factors that influence specialty choice, including the value of procedural work, intellectual content of specialty and flexibility of working arrangements (Harris et al., 2005; Sivey et al., 2010). Longitudinal data on the evolution of earnings over medical careers and the determinants of specialty choice would be an important piece of future research.

This study has some limitations. First, the data on earnings and hours worked are self-reported and may suffer from reporting errors (such as under-reporting or over-reporting), which are common in surveys of individuals and households (Moore et al., 2000). Reporting errors, which are systematically related with the explanatory variables can lead to biased results. Unfortunately, we do not have independent sources of doctors' earnings

\footnotetext{
${ }^{4}$ The estimates of the gender differential in annual earnings in Bashaw and Heywood (2001) and Gravelle and Hole (2008) were obtained through using the Oaxaca decomposition analysis and controlling for the number of hours worked.

${ }^{5}$ The authors did not include the number of hours worked in the regression equation for annual income.

${ }^{6}$ Sloan (1970) estimates the returns to investment from different medical specialty training programs in the USA using data on lifetime earnings, length of residency training and cost of tuition and fees.
} 
data to validate the self-reported measures in the MABEL data. From a probit model of non-response to the gross earnings questions, there is only weak evidence that non-respondents may have had higher earnings, so mean earnings may at most have been slightly underestimated. It was not possible to double-check for this in a selection model as no instrumental variables could be identified that influenced response to the earnings question but not earnings. In terms of the self-reported hours worked, Joyce et al. (2010) found that the distribution of hours worked by age groups in the MABEL baseline cohort is nationally representative. Also in the data preparation prior to analysis, extensive checking and cross validation of earnings and hours were carried out to maximise the accuracy of the data. However, we acknowledge that reporting error may still be present in the data despite our best efforts. Second, in addition to the hours variables, explanatory variables, such as selfemployment and the self-reported job characteristics, may be endogenous. For example, if selection into selfemployment is based on unobservable characteristics and if these unobservable factors also influence earnings, the estimates on the returns to self-employment may be biased. A number of studies have examined earnings differentials in self-employment versus salaried employment and the role it plays in influencing decisions between the two employment types. This literature generally finds no evidence of self-selection (Le 1999). A thorough investigation of the potential endogeneity of self-employment and job characteristic variables will not be conducted in this paper and will be deferred to the future when further waves of the MABEL data become available.

Although the estimates do not have causal interpretations, the results in this paper have potential policy implications and indicate avenues for further research on the medical workforce. The large gender differential has implications for healthcare costs, as the proportion of female graduates is now around 55\%. In addition to the effect of earnings on labour supply of female GPs, the earnings differential has implications on the overall growth of the gap in earnings between GPs and specialists, particularly as the proportion of female doctors in the workforce grows.

The higher returns to experience for specialists suggest that GPs have fewer opportunities to advance their careers in ways that increase their earnings once GPs are established in private practice; they essentially do the same job for the rest of their careers. Although more experienced GPs could charge higher prices, patients may be more price sensitive and have less knowledge about the quality of different GPs. Specialists are more likely to be rewarded in the market through public hospital employers recognising experience in the construction of salaried pay scales with increments for years of experience and the use of bonuses and through the system of GP referral where GPs refer patients to the most experienced specialists and where patients are less price sensitive.

General practitioners in non-metropolitan areas are eligible for a variety of payments through government incentive schemes, and this is reflected in the results. A lower number of GPs per capita also leads to higher earnings, which has implications for the role of competition and access to care in GP markets. The fees GPs can charge are unregulated and are clearly related to overall earnings. GP density will be endogenous because of the selection of GPs into geographic areas, but further research on the role of competition where fees are unregulated will be important.

There also were significant differences in earnings across different medical specialties. It would be of interest to explore whether the pay differentials between specialties are in line with demand for these specialties (and potential shortages) or whether they are mainly driven by the cost of training and complexity of required skills. If pay differentials are out of line with demand for the relevant services, this might be another research area of interest for policymakers.

Although we do not have detailed data on the characteristics of patients, the influence of patient and population characteristics on earnings was captured by some of the area-level variables and a question on whether the doctor perceived their patients to have 'complex health and social problems'. ${ }^{7}$ An effective remuneration system that leads to improvements in population health would imply that earnings were higher in areas of,

\footnotetext{
${ }^{7}$ An earlier version of the model included the number of patients seen per week, but this was not statistically significant in any of the models once other factors had been controlled for.
} 
or for patients with, high 'need' for health care. Although it is difficult to interpret area-level measures, GPs working in affluent areas had lower earnings. However, using the more direct measure of patient complexity, the earnings of GPs were unrelated to the perceived complexity of patients, whereas specialists earned more if their patients were considered to be less complex. We used a rudimentary measure of patients' complexity, and so further research into the relationship between earnings and the characteristics of patients is necessary. Any remuneration scheme should provide higher rewards to doctors for patients most in need of health care and where their capacity to benefit from treatment is high.

\section{CONFLICT OF INTEREST}

The authors declare that there is no conflict of interest.

\section{APPENDIX A: MARGINAL EFFECTS ON PROBABILITY OF RESPONSE TO GROSS INCOME}

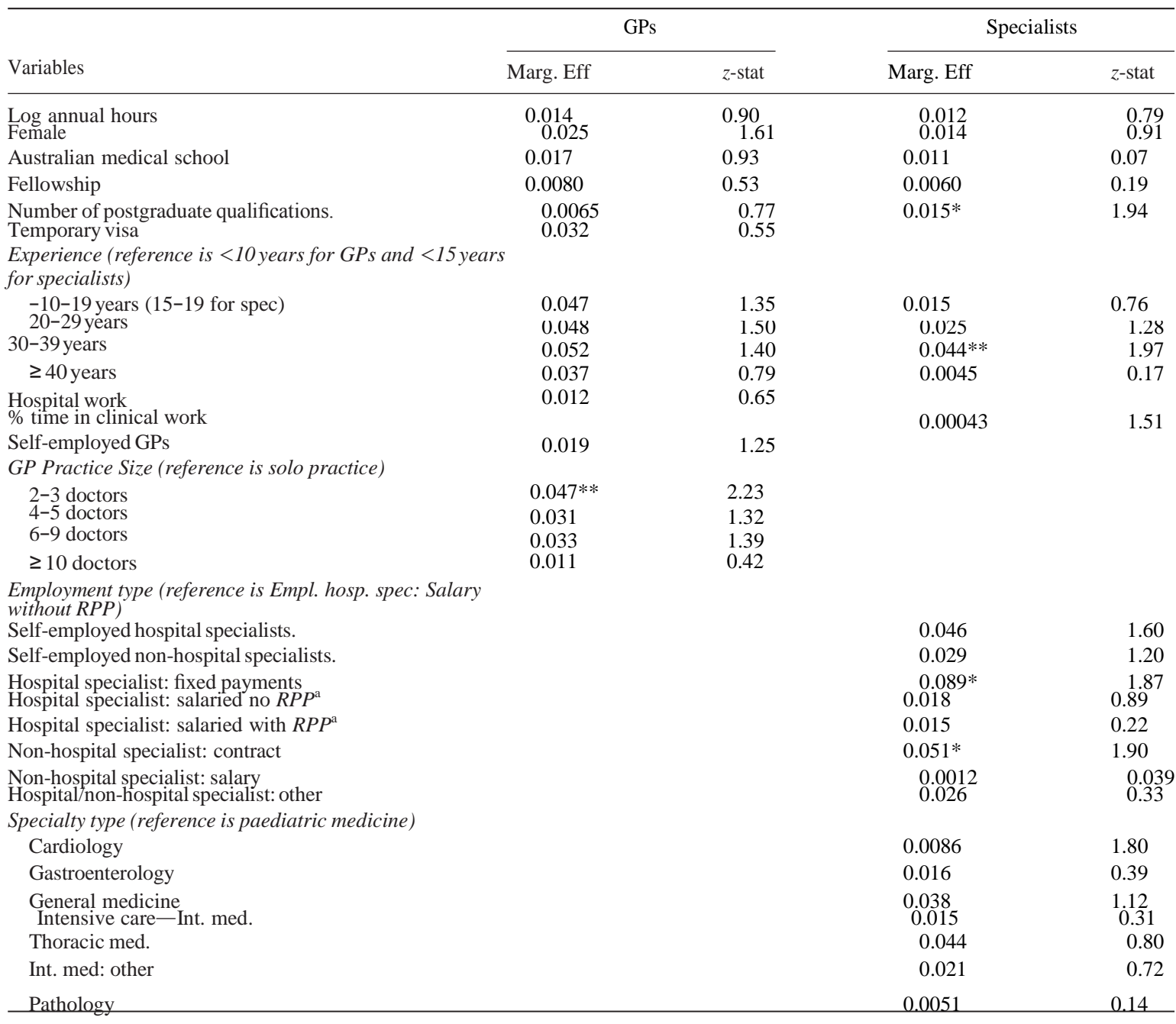


APPENDIX A. (continued)

\begin{tabular}{|c|c|c|c|c|}
\hline Variables & Marg. Eff & $z$-stat & Marg. Eff & $z$-stat \\
\hline $\begin{array}{l}\text { General surgery } \\
\text { Orthopaedic surgery }\end{array}$ & & & $\begin{array}{r}0.0032 \\
0.028\end{array}$ & $\begin{array}{r}0.096 \\
0.89\end{array}$ \\
\hline Surgery: other & & & 0.020 & 0.69 \\
\hline Anaesthesia & & & $0.044 *$ & 1.88 \\
\hline $\begin{array}{l}\text { Diagnostic radiology } \\
\text { Emergency med. }\end{array}$ & & & $\begin{array}{l}0.00081 \\
0.069^{* * *}\end{array}$ & $\begin{array}{r}0.023 \\
2.83\end{array}$ \\
\hline Obstetrics/gynaecology & & & 0.011 & 0.35 \\
\hline Ophthalmology & & & 0.040 & 0.87 \\
\hline Psychiatry & & & 0.016 & 0.60 \\
\hline Other & & & 0.0110 & 0.36 \\
\hline Do after-hour and on-call work & 0.0059 & 0.41 & $0.033^{*}$ & 1.90 \\
\hline Patients have complex health/social problems & 0.013 & 0.95 & 0.017 & 1.24 \\
\hline Unpredictable work hours & 0.0101 & 0.68 & 0.015 & 1.14 \\
\hline Limited opportunity for social interaction & $0.049 * *$ & 1.96 & $0.031 *$ & 1.78 \\
\hline Good employment opportunity for partner & 0.013 & 0.98 & 0.0063 & 0.53 \\
\hline \multicolumn{5}{|l|}{ State of work (reference is NSW) } \\
\hline VIC & 0.0064 & 0.38 & 0.0074 & 0.51 \\
\hline QLD & 0.0058 & 0.25 & $0.033^{*}$ & 1.66 \\
\hline SA & 0.022 & 0.95 & 0.0079 & 0.36 \\
\hline WA & $0.038 *$ & 1.94 & 0.029 & 1.40 \\
\hline TAS & $\begin{array}{c}0.062 * * \\
0.012\end{array}$ & $\begin{array}{c}2.40 \\
0.26\end{array}$ & $\begin{array}{r}0.0096 \\
0.024\end{array}$ & $\begin{array}{c}0.24 \\
0.62\end{array}$ \\
\hline NT & 0.054 & 0.63 & 0.099 & 0.77 \\
\hline \multicolumn{5}{|l|}{$A S G C$ (reference is major city) } \\
\hline Inner regional & 0.017 & 0.71 & 0.013 & 0.59 \\
\hline Other & 0.017 & 0.58 & $0.056 * *$ & 2.09 \\
\hline Standardised GP density & 0.0049 & 0.86 & & \\
\hline SEIFA & 0.0035 & 1.04 & & \\
\hline Log of median house price & 0.026 & 1.59 & 0.015 & 1.11 \\
\hline$N$ & 2378 & & 3284 & \\
\hline
\end{tabular}

$* * * p<0.01, * * p<0.05, * p<0.1$.

${ }^{a} R P P$ : Rights to private practice

\section{ACKNOWLEDGEMENTS}

We thank the two anonymous referees for their helpful comments.

This work was supported by a National Health and Medical Research Council Health Services Research Grant (454799) and the Commonwealth Department of Health and Ageing. The views in this paper are those of the authors alone. The authors thank the two anonymous referees for their helpful comments. The authors also thank the doctors who gave their valuable time to participate in MABEL and the other members of the MABEL team for data cleaning and comments on drafts of this paper: Danny Hills, Daniel Kuehnle, Anne Leahy, Matthew McGrail, Michelle McIsaac, Stefanie Schurer, Durga Shrestha and Peter Sivey. The study was approved by the University of Melbourne Faculty of Economics and Commerce Human Ethics Advisory Group (Ref. 0709559) and the Monash University Standing Committee on Ethics in Research Involving Humans (Ref. CF07/1102-2007000291).

\section{REFERENCES}

Australian Bureau of Statistics. 2003. ASGC remoteness classification: purpose and use, Census Geography Paper No. 03/01, Canberra. Available at: http://www.abs.gov.au/websitedbs/D3110122.NSF/0/f9c96fb635cce780ca256d420005dc02? OpenDocument [Accessed June 2010].

Australian Bureau of Statistics. 2004. Average Weekly Earnings, Australia, August 2004, No.6302.0, Canberra. 
Available at: http://www.abs.gov.au/AUSSTATS/abs@.nsf/Lookup/6302.0Main+Features1Aug\%202004?OpenDocument [Accessed June 2010].

Australian Bureau of Statistics. 2007. Average Weekly Earnings, Australia, August 2007, No.6302.0, Canberra. Available at: http://www.abs.gov.au/AUSSTATS/abs@.nsf/allprimarymainfeatures/7C25BF2EF91812B1CA2573F500151FEB? opendocument [June 2010].

Australian Bureau of Statistics. 2008. An introduction to socioeconomic indices for areas: 2006, No. 2039.0, Canberra. Available at: http://www.abs.gov.au/AUSSTATS/abs@.nsf/DetailsPage/2039.02006?OpenDocument [Accessed June 2010].

Australian Institute of Health and Welfare. 2009. Health expenditure Australia 2007-08. Health and welfare expenditure series no. 37. Cat. no. HWE 46. AIHW: Canberra.

Australian Medical Association. 2006. Safe hours = safe patients. AMA safe hours audit 2006. Kingston ACT.

Baltagi BH, Bratberg E, Holmaa TH. 2005. A panel data study of physicians' labour supply: the case of Norway. Health Economics 14(10): 1035-1045.

Bashaw DJ, Heywood JS. 2001. The gender earnings gap for US physicians: has equality been achieved? Labour 15: 371-391.

Baum CF, Schaffer ME, Stillman S. 2003. Instrumental variables and GMM estimation and testing. Working paper No 545, Department of Economics, Boston College.

Blinder AS. 1973. Wage discrimination: reduced form and structural estimates. Journal of Human Resource 8: 436-455.

Bodenheimer T, Berenson RA, Rudolf P. 2007. The primary care-specialty income gap: Why it matters. Annals of Internal Medicine 146: 301-306.

Elliot RF, Ma A, Scott A, Bell D, Roberts E. 2007. Geographically differentiated pay in the labour market for nurses. Journal of Health Economics 26: 190-212.

Fortin N, Lemieux T, Firpo S. 2010. Decomposition methods in economics. NBER Working Paper No. 16045.

Gravelle H, Hole AR. 2008. Measuring and testing for gender discrimination in professions: the case of English GPs. Discussion Paper 2008/28, Department of Economics and Related Studies, University of York.

Harris MG, Gavel PH, Young JR. 2005. Factors influencing the choice of specialty of Australian medical graduates. Medical Journal of Australia 183: 295-300.

Hayashi, F. 2000. Econometrics. Princeton University Press: New Jersey.

Headen AE. 1990. Wage, returns to ownership, and fee responses to physician supply. The Review of Economics and Statistics 72: 30-37.

Hurley J. 1991. Physicians' choices of specialty, location, and mode: A reexamination within an interdependent decision framework. Journal of Human Resources 26(1): 47-71.

Ikenwilo D, Scott A. 2007. The effects of pay and job satisfaction on the labour supply of hospital consultants. Health Economics 16: 1303-1318.

Jann B. 2008. The Blinder-Oaxaca decomposition for linear regression models. The Stata Journal 8(4): 453-479.

Jones FL. 1983. On decomposing the wage gap: a critical comment on Blinders' method. The Journal of Human Resources 18: $126-130$.

Jones FL, Kelly J. 1984. Decomposing differences between groups. A cautionary note on measuring discrimination. Sociological Methods and Research 12: 323-343.

Joyce CM, Scott A, Jeon S, Humphreys J, Kalb G, Witt J, Leahy A. 2010. The "Medicine in Australia: Balancing Employment and Life (MABEL) longitudinal survey - Protocol and baseline data for a prospective cohort study of Australian doctors' workforce participation. BMC Health Services Research 10: 50. http://www.biomedcentral.com/ $1472-6963 / 10 / 50$

Langwell, KM. 1982. Factors affecting the incomes of men and women physicians: further explorations. Journal of Human Resources 17: 261-275.

Le A. 1999. Empirical studies of self employment. Journal of Economic Surveys 13: 381-416.

Lillard L, Smith JP, Welch F. 1986. What do we really know about wages? The importance of nonreporting and census imputation. The Journal of Political Economy 94(3): 489-506.

Mincer J. 1997. The Production of Human Capital and the Life Cycle of Earnings: Variations on a Theme. Journal of Labor Economics 15: S26-S47.

Moore JC, Stinson LL, Welniak EJ Jr. 2000. Income Measurement Error in Surveys: A Review. Journal of Official Statistics 16: 331-361.

Morris S, Goudie R, Sutton M, Gravelle H, Elliott R, Hole AR, Ma A, Sibbald B., Skatun D. 2010. Determinants of general practitioners' wages in England. Health Economics. doi: 10.1002/hec.1573

Nicholson S. 2002. Physician Specialty Choice under Uncertainty. Journal of Labor Economics 20(4): 816-847.

Oaxaca R. 1973. Male-female wage differentials in urban labour markets. International Economic Review 14: 693-709. 
Oaxaca R, Ransom, MR. 1999. Identification in detailed wage decomposition. The Review of Economics and Statistics 81(1): $154-157$

Ohsfeldt RL, Culler, SD. 1986. Differences in income between male and female physicians. Journal of Health Economics 5: 225246

Riphahn R, Serfling, O. 2005. Item non-response on income and wealth questions. Empirical Economics 30: 521-538.

Rizzo, JA, Blumenthal, D. 1994. Physician labor supply: do income effects matter? Journal of Health Economics 13: 433-453.

Rosen S 1986. The theory of equalizing differences. In The Handbook of Labour Economics, Ashenfelter O, Layard R (eds). Elsevier Science Publishers: Amsterdam, 641-692.

Rosenblatt, RA, Andrilla, CH. 2005. The impact of U.S medical students' debt on their choice of primary care careers: an analysis of data from the 2002 medical school graduation questionnaire. Academic Medicine 80: 815-819.

Sæther EM. 2005. Physicians' Labour Supply: The wage impact on hours and practice combinations. Labour 19: 673-703.

Sivey P, Scott A, Witt J, Joyce CM, Humphreys JS. 2010. Why Junior Doctors Don't Want to Become General Practitioners: A Discrete Choice Experiment from the MABEL Longitudinal Study of Doctors. Melbourne Institute Working Paper Series No.17/10. Melbourne: Melbourne Institute of Applied Economic and Social Research, The University of Melbourne.

Sloan F. 1970. Lifetime earnings and physicians choice of specialty'. Industrial and Labour Relations Review 24: 47-56. Thornton J. 2000. Physician choice of medical specialty: do economic incentives matter? Applied Economics 32(11): $1419-1428$.

Yun M-S. 2005. A simple solution to the identification problem in detailed wage decompositions. Economic Inquiry 43: 766-772. 


\section{University Library}

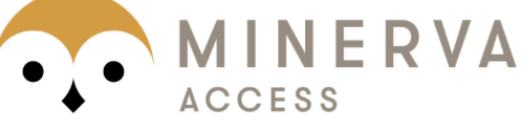

A gateway to Melbourne's research publications

Minerva Access is the Institutional Repository of The University of Melbourne

Author/s:

Cheng, TC;Scott, A;Jeon, S-H;Kalb, G;Humphreys, J;Joyce, C

Title:

WHAT FACTORS INFLUENCE THE EARNINGS OF GENERAL PRACTITIONERS AND MEDICAL SPECIALISTS? EVIDENCE FROM THE MEDICINE IN AUSTRALIA: BALANCING EMPLOYMENT AND LIFE SURVEY

Date:

2012-11-01

Citation:

Cheng, T. C., Scott, A., Jeon, S. -H., Kalb, G., Humphreys, J. \& Joyce, C. (2012). WHAT FACTORS INFLUENCE THE EARNINGS OF GENERAL PRACTITIONERS AND MEDICAL SPECIALISTS? EVIDENCE FROM THE MEDICINE IN AUSTRALIA: BALANCING EMPLOYMENT AND LIFE SURVEY. HEALTH ECONOMICS, 21 (11), pp.1300-1317. https:// doi.org/10.1002/hec. 1791.

Persistent Link:

http://hdl.handle.net/11343/112382 